Research Article

\title{
Melamine Recognition: Molecularly Imprinted Polymer for Selective and Sensitive Determination of Melamine in Food Samples
}

\author{
Mohadese Biabani $\left(\mathbb{D},{ }^{1}\right.$ Azizollah Nezhadali $\left(\mathbb{D},{ }^{1}\right.$ Ahmad Nakhaei $\left(\mathbb{D},{ }^{2}\right.$ \\ and Hossein Nakhaei $\left(D^{3}\right.$ \\ ${ }^{1}$ Department of Chemistry, Payame Noor University, P.O. Box 19395-4697, Tehran, Iran \\ ${ }^{2}$ Young Researchers and Elite Club, Mashhad Branch, Islamic Azad University, Mashhad, Iran \\ ${ }^{3}$ Health Promotion Research Center, Zahedan University of Medical Sciences, Zahedan, Iran \\ Correspondence should be addressed to Ahmad Nakhaei; nakhaei_a@yahoo.com
}

Received 19 August 2020; Revised 5 October 2020; Accepted 20 October 2020; Published 4 November 2020

Academic Editor: Adil Denizli

Copyright (c) 2020 Mohadese Biabani et al. This is an open access article distributed under the Creative Commons Attribution License, which permits unrestricted use, distribution, and reproduction in any medium, provided the original work is properly cited.

In this study, a sensitive and selective sensor is constructed to measure the melamine (MEL) using molecular imprinting polymer (MIP) technique. Chemical and electrochemical techniques are used to construct the MIP and quantitative measurements. The constructed sensor was modified with GO- $\mathrm{Fe}_{3} \mathrm{O}_{4} @ \mathrm{SiO}_{2}$ nanocomposite. Screening and optimization of factors are done using statistical methods, including Plackett-Burman design (PBD) and central composite design (CCD). Under the optimized conditions, an MIP sensor showed a linear range from $5.0 \times 10^{-7}$ to $1.0 \times 10^{-5} \mathrm{M} \mathrm{MEL}$ concentration with a correlation coefficient $\left(R^{2}\right)$ of 0.9997 . The limit of detection was obtained $(0.028 \mu \mathrm{M})$ with a highly reproducible response ( $\mathrm{RSD} 2.15 \%, n=4$ ). The electrochemical sensor showed good results for the determination of MEL in food samples.

\section{Introduction}

Melamine (MEL) (Scheme 1), triamino triazine, is an organic compound with the formula $\mathrm{C}_{3} \mathrm{H}_{6} \mathrm{~N}_{6}$, which contains $67 \%$ nitrogen by mass. MEL can be combined with formaldehyde and other agents to produce melamine resins. Such resins are characteristically durable thermosetting plastic used in high-pressure decorative laminates and dry erase boards. MEL foam is used as insulation, soundproofing material, and polymeric cleaning products. Besides, it is used in adhesives, paints, permanent-press fabrics, textile finishes, tarnish inhibitors, paper coatings, and fertilizer mixtures [1]. Because it has protein-like properties, it is sometimes illegally added to food products like pet foods, liquid milk, yogurts, egg, frozen desserts, powdered milk, cereal products, confectionaries, cakes and biscuits, protein powders, and some processed foodstuffs to increase the apparent protein content. Ingestion of MEL may lead to reproductive damage, or bladder or kidney stones, and bladder cancer. It is also an irritant when inhaled or in contact with the skin or eyes. The United Nations' food standards body has set the maximum amount of MEL allowed in powdered infant formula to $1 \mathrm{mg} / \mathrm{kg}$ and the amount of the chemical allowed in other foods and animal feed to $2.5 \mathrm{mg} / \mathrm{kg}$. While not legally binding, the levels allow countries to ban the importation of products with excessive levels of MEL [2-4].

Various analytical methods are described for the determination of very low amounts of MEL in different samples, including gas chromatography [5], capillary zone electrophoresis [6], high-performance liquid chromatography [7], and reversed-phase high-performance liquid chromatography with solid-phase extraction [8]. Although these methods have been successfully employed, they are expensive and time-consuming and require high skill to use. 
On the contrary, electrochemical methods are simple, fast, inexpensive, and useful research tool for investigating a large range of molecules, and they can be an interesting alternative to other instrumental techniques. MEL is a nonelectroactive molecule, but using some electroactive materials, called probes, electrochemical methods can be used to measure MEL [9]. [Fe $\left.(\mathrm{CN})_{6}\right]^{3-} /\left[\mathrm{Fe}(\mathrm{CN})_{6}\right]^{4-}$ solution is a common electrochemical indicator for nonelectroactive molecules [10].

One of the effective separation methods that have appeared in recent years is molecularly imprinting polymers (MIPs). MIP is synthesized by simultaneous polymerization of functional and cross-linking monomers in the presence of the template molecule and used as a powerful, sensitive, and selective absorber for the identification and measurement of the template molecule. MIPs have several advantages, including low cost, good physical and chemical stability, high selectivity, and simplicity [11-15]. MIPs have been widely used in solid-phase extraction [16], chromatographic separation [17], drug release [18], reaction catalysts [19], enzyme mimics [20], cancer biomarkers and viruses [21], and sensors [22-24]. Precipitation polymerization for producing MIPs is more popular because, in this method, regular shape MIP beads are obtained, and the polymeric chains are grown individually to microspheres. In addition, this method does not need the porogen agents and has easy and fast procedure. Because of fantastic advantages of chemical methods for constructing MIP and electrochemical methods for determination, their combination can be a smart tool to achieve a new selective and sensitive technique [25-27]. Pyrrole is an interesting functional monomer because it is suitable in a natural $\mathrm{pH}$ range, and its polymer is made easily with a high chemical and electrochemical stability [28-30]. Low conductivity is the most common problem of MIP sensors that lead to decrease in electron transfer and low sensitivity. It is because of forming a thick polymeric film on the surface of electrode. The sensitivity and performance of the sensor are enhanced by emerging MIP with nanoparticles [31] that this construction leads to the high surface-to-volume ratio, which results in an increase in surface area per weight unit of polymer. In addition, due to the geometric characteristics of $\mathrm{MIP} /$ nanoparticles, the penetration of the target molecule into the polymer cavities is increased, resulting in a faster mass transfer rate [32-36]. Nanomaterials such as carbon nanotubes (CNTs), graphene oxide (GO), and metal oxide nanoparticles such as $\mathrm{ZnO}, \mathrm{Fe}_{3} \mathrm{O}_{4}, \mathrm{CuS}, \mathrm{SiO}_{2}$, and $\mathrm{TiO}_{2}$ are suitable to improve the selectivity and sensitivity of MIPs. In addition, core-shell nanostructures are a kind of new nanomaterials. In these nanostructures, one nanoparticle is coated by another nanoparticle. Many properties of coreshell nanoparticles are more efficient and improved than single nanoparticles. Due to the unique properties of these nanostructures including the unique mechanical, optical, and thermal properties, use of core-shell nanoparticles has been increasing in recent years $[37,38]$. In these structures, the shell is used to protect the core particles from physical and chemical changes. Another potential purpose of the shell is to improve the activity of the core particle surface as well as stability and scattering. Through surface coating, core particles can have magnetic, optical, and catalytic properties that are unique to shell particles [39-41]. In the present work, to take advantage of the core-shell nanoparticles, using the sol-gel method, the surface of the $\mathrm{Fe}_{3} \mathrm{O}_{4}$ nanoparticles deposited on $\mathrm{GO}$ nanoparticles was coated with a layer of $\mathrm{SiO}_{2}$ nanoparticles, and finally, the $\mathrm{GO}-\mathrm{Fe}_{3} \mathrm{O}_{4} @ \mathrm{SiO}_{2}$ nanocomposite was made.

In this study, an electrochemical sensor was developed for the determination of MEL. First, chemical polymerization of pyrrole was carried out in the presence of MEL, and then, by removing the MEL from the MIP holes, it deposited on the bare of Pt electrodes to construct the electrochemical sensor as a selective and sensitive microsolid-phase preconcentration sensor to the determination of MEL. Multivariate techniques including Plackett-Burman design (PBD) and central composition design (CCD) were used for screening and optimization of the factors affecting the performance of extraction and determination of MEL, respectively.

\section{Results and Discussion}

Cyclic voltammetry $(\mathrm{CV})$ is a reversible electrochemical technique used to study the electrochemical behavior of electroactive species. However, for nonelectroactive species, some electroactive materials are used as probes. The solution of $\mathrm{Fe}(\mathrm{CN})_{6}{ }^{4-}$ and $\mathrm{Fe}(\mathrm{CN})_{6}{ }^{3-}$ is one of the most popular probes used in the analytical process [42]. In the present work, the oxidation current of $\mathrm{MIP} / \mathrm{GO}-\mathrm{Fe}_{3} \mathrm{O}_{4} @$ $\mathrm{SiO}_{2} / \mathrm{Pt}$ electrode as a working electrode in $0.3 \mathrm{M}$ solution of $\left[\mathrm{Fe}(\mathrm{CN})_{6}\right]^{4-}$ and $\left[\mathrm{Fe}(\mathrm{CN})_{6}\right]^{3-}$ was measured before loading the electrode in MEL standard solution $\left(I_{p}\right)$. After loading the MIP/GO- $\mathrm{Fe}_{3} \mathrm{O}_{4} @ \mathrm{SiO}_{2} / \mathrm{Pt}$ electrode with the standard solution of MEL, the oxidation current $\left(\mathrm{I}_{\mathrm{MIP}}\right)$ of $0.3 \mathrm{M}$ solution of $\left[\mathrm{Fe}(\mathrm{CN})_{6}\right]^{4-}$ and $\left[\mathrm{Fe}(\mathrm{CN})_{6}\right]^{3-}$ was measured and the oxidation current decrease $\left(\Delta I=I_{p}-I_{\mathrm{MIP}}\right)$ was calculated as the amount of the MEL molecules trapped in the imprinted polymer holes.

\subsection{Experimental Design}

2.1.1. Screening of Significant Factors. To maximize the amount and accuracy of information that was received from a given set of experimental runs, a planned sequence of experiments linking changes in input variables with changes in $\Delta I$ was designed. This experimental design facilitated the study of how responses change and interact at different variable settings. The $\mathrm{PBD}$ design, as a great value in screening experiments, identifies the effective factors and reduces the number of runs [43]. In the present work, the nine factors were chosen for the investigation, which are the amount of $\mathrm{GO}-\mathrm{Fe}_{3} \mathrm{O}_{4} @ \mathrm{SiO}_{2}$ (g) (A), [PY]/[MEL] (B), extraction solvent $(\mathrm{C})$, the amount of $\mathrm{FeCl}_{3}(\mathrm{~g})(\mathrm{D})$, stirring rate of polymerization solution (r.p.m.) (E), the amount of $\mathrm{MIP} / \mathrm{GO}-\mathrm{Fe}_{3} \mathrm{O}_{4} @ \mathrm{SiO}_{2}(\mathrm{~g})(\mathrm{F})$, the polymerization time (h) $(\mathrm{G})$, stirring rate of loading solution (r.p.m) (H), and loading time ( $\mathrm{min})(\mathrm{J})$. A low and high level was considered for each of the variables. A PBD design was carried out for nine 
TABLE 1: Results of PB experimental design matrix.

\begin{tabular}{lcccccccccc}
\hline $\begin{array}{l}\text { Run } \\
\text { order }\end{array}$ & $\mathrm{A}$ & $\mathrm{B}$ & $\mathrm{C}$ & $\mathrm{D}$ & $\mathrm{E}$ & $\mathrm{F}$ & $\mathrm{G}$ & $\mathrm{H}$ & $\mathrm{J}$ & $\begin{array}{c}\Delta I \\
(\mu \mathrm{A})\end{array}$ \\
\hline 1 & 0.6 & 15 & Acetonitrile & 0.3 & 150 & 0.005 & 24 & 500 & 10 & 21.71 \\
2 & 0.6 & 25 & Methanol & 0.8 & 150 & 0.005 & 12 & 500 & 10 & 19.53 \\
3 & 0.2 & 25 & Acetonitrile & 0.3 & 450 & 0.005 & 12 & 200 & 10 & 19.70 \\
4 & 0.6 & 15 & Acetonitrile & 0.8 & 150 & 0.05 & 12 & 200 & 5 & 18.80 \\
5 & 0.6 & 25 & Methanol & 0.8 & 450 & 0.005 & 24 & 200 & 5 & 19.64 \\
6 & 0.6 & 25 & Acetonitrile & 0.3 & 450 & 0.05 & 12 & 500 & 5 & 19.79 \\
7 & 0.2 & 25 & Acetonitrile & 0.8 & 150 & 0.05 & 24 & 200 & 10 & 18.67 \\
8 & 0.2 & 15 & Acetonitrile & 0.8 & 450 & 0.005 & 24 & 500 & 5 & 21.41 \\
9 & 0.2 & 15 & Methanol & 0.8 & 450 & 0.05 & 12 & 500 & 10 & 19.81 \\
10 & 0.6 & 15 & Methanol & 0.3 & 450 & 0.05 & 24 & 200 & 10 & 21.37 \\
11 & 0.2 & 25 & Methanol & 0.3 & 150 & 0.05 & 24 & 500 & 5 & 18.63 \\
12 & 0.2 & 15 & Methanol & 0.3 & 450 & 0.005 & 12 & 200 & 5 & 18.76 \\
\hline
\end{tabular}<smiles>Nc1nc(N)nc(N)n1</smiles>

Scheme 1: Structure of melamine (MEL).

factors, consisting of 12 randomized runs. Table 1 shows the experimental results for the 12-run PBD design.

Figures 1(a) and 1(b) illustrate the standardized Pareto plot of the main effects for PBD design and main effect plot for voltammetric response at $95 \%$ confidence level $(p \leq 0.05)$, respectively. The Pareto plot shows that effects of $\mathrm{B}, \mathrm{E}$, and $\mathrm{G}$ factors are most important to the analytical process. The main effects plot for $\Delta I$ shows the effective level of each factor. Therefore, B factor in the low level and $\mathrm{E}$ and $G$ factors in the high level have more impact on the experiment and need to be optimized more accurately.

2.1.2. Optimization. CCD is a simple and useful design used to optimize a wide range of empirical effective factors [44]. A three-level CCD with 20 runs was carried out for optimization of the process after screening by PBD design. The results are shown in Table 2 for each experiment.

The aim of this analysis is to increase the $\Delta I$, which is a measure of the amount of the MEL molecules trapped in imprinted polymer holes. The following equation was obtained based on the regression analysis:

$$
\begin{aligned}
\Delta I= & -13.96+4.138 \mathrm{~B}-0.00837 \mathrm{E}+370.2 \mathrm{G}-0.11227 \mathrm{~B}^{2}+0.000007 \mathrm{E}^{2} \\
& +1933 \mathrm{G}^{2}+0.001040 \mathrm{BE}-25.525 \mathrm{BG}-0.2758 \mathrm{EG} .
\end{aligned}
$$

Using analysis of variance (ANOVA), presented in Table 3, the validation of the statistical result was analyzed. $R^{2}$ and $R_{\text {adj }}^{2}$ for models were obtained as $99.29 \%$ and $98.65 \%(p \leq 0.05)$, respectively. The lack-of-fit $P$ value was obtained as 0.171 . According to the response surface optimization, the optimal conditions were obtained as 11.8 and 300 r.p.m. and $0.07 \mathrm{~g}$ for $\mathrm{B}, \mathrm{E}$, and $\mathrm{G}$ factors, respectively.

2.1.3. Surface Characterization. The morphological structures of $\mathrm{GO}-\mathrm{Fe}_{3} \mathrm{O}_{4} @ \mathrm{SiO}_{2}$ nanocomposite (Figure 2(a)), $\mathrm{MIP} / \mathrm{GO}-\mathrm{Fe}_{3} \mathrm{O}_{4} @ \mathrm{SiO}_{2}$ (Figure 2(b)), and NIP/GO-Fe $\mathrm{O}_{4} @$ $\mathrm{SiO}_{2}$ (Figure 2(c)) were investigated by scanning electron microscopy (SEM). Figure 3 shows image of the amorphous $\mathrm{GO}-\mathrm{Fe}_{3} \mathrm{O}_{4} @ \mathrm{SiO}_{2}$ nanocomposite at a magnification of 50000. Figure 2(b) shows a uniform imprinted polymeric film of a network of holes that has spread to the surface of the GO- $\mathrm{Fe}_{3} \mathrm{O}_{4} @ \mathrm{SiO}_{2}$ nanocomposite. The SEM images (Figures 2(b) and 2(c)) demonstrate the significant morphological difference between MIP/GO-Fe $\mathrm{O}_{4} @ \mathrm{SiO}_{2}$ and NIP/GO-Fe ${ }_{3} \mathrm{O}_{4} @ \mathrm{SiO}_{2}$, respectively. The polymerization conditions, such as the type of [PY]/[MEL], polymerization solvent, polymerization time, are effective on imprinted polymer [45]. The SEM imaging of MIP clearly shows an irregular morphology that facilitates the fast binding of template molecules to the polymer [46]. The surface of MIP/ $\mathrm{GO}-\mathrm{Fe}_{3} \mathrm{O}_{4} @ \mathrm{SiO}_{2}$ exhibits more porosity than that of NIP/ GO-Fe $\mathrm{O}_{4} @ \mathrm{SiO}_{2}$ (Figures 2(b) and 2(c)). The presence of the MEL in the polymerization solution causes the formation of holes in the MIP film and changes the morphology of the polymer [47].

2.1.4. The Molding Effect. To investigate of the presence of holes on the surface of MIP, the CV voltammograms of the $0.3 \mathrm{M}$ probe solution at the surface unloaded MIP/GO$\mathrm{Fe}_{3} \mathrm{O}_{4} @ \mathrm{SiO}_{2} / \mathrm{Pt}$ (a), loaded NIP/GO-Fe $\mathrm{O}_{4} @ \mathrm{SiO}_{2} / \mathrm{Pt}$ (b), loaded MIP/Pt (c), and loaded MIP/GO-Fe $\mathrm{O}_{4} @ \mathrm{SiO}_{2} / \mathrm{Pt}$ (d) in the potential range of $-0 / 500$ to $0 / 500 \mathrm{~V}$ were investigated. The results are shown in Figure 3. For this purpose, the MIP/GO-Fe $\mathrm{O}_{4} @ \mathrm{SiO}_{2} / \mathrm{Pt}$ sensor was manufactured according to the optimum conditions. Before loading MEL, it was immersed in the $0.3 \mathrm{M}$ probe solution, and its cyclic voltammogram was recorded (a). Then, the sensor was loaded under optimum conditions, and the cyclic voltammogram of $0.3 \mathrm{M}$ probe solution was again recorded (d). By comparing (a) and (d), it can find that when the MIP cavities are empty, $\mathrm{Fe}^{2+}$ and $\mathrm{Fe}^{3+}$ ions can easily penetrate to the electrode surface and are oxidized and resuscitated, but the sharp decrease in the current in (d) shows the blocked cavities after loading the sensor well. The cavities created during the polymerization process are completely consistent with the MEL molecules in terms of shape, size, and functional groups. By comparing (d) and (b), the molding effect is well known. In other words, during the polymerization process, the complex of PYMEL is formed because of hydrogen bonds between the $\mathrm{N}-\mathrm{H}$ group of $\mathrm{PY}$ monomers and $\mathrm{NH}_{2}$ group of MEL molecules. As a result, the MEL molecules are trapped due to the formation of hydrogen bonds with the PY monomers in the polymer tissue, which increases the porosity of the MIP. Therefore, after loading, the penetration of $\mathrm{Fe}^{2+}$ and $\mathrm{Fe}^{3+}$ ions into the electrode surface will be less than NIP. Comparison of (d) and (c) shows the modification of MIP with $\mathrm{GO}-\mathrm{Fe}_{3} \mathrm{O}_{4} @ \mathrm{SiO}_{2}$ nanocomposite and demonstrates 


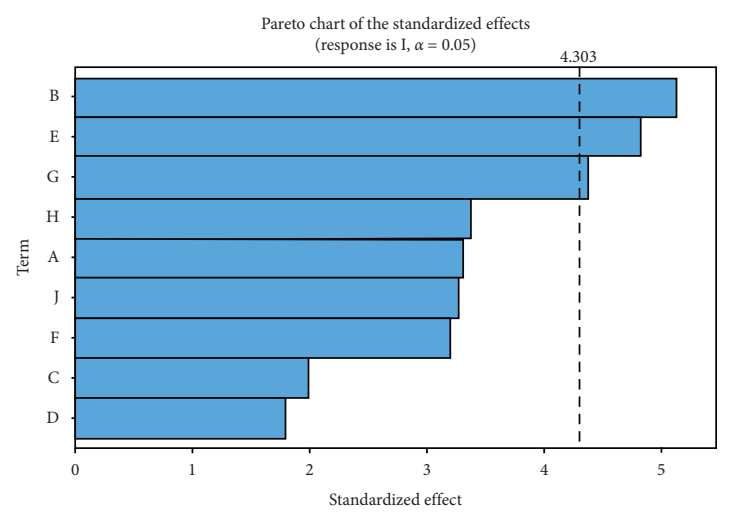

(a)

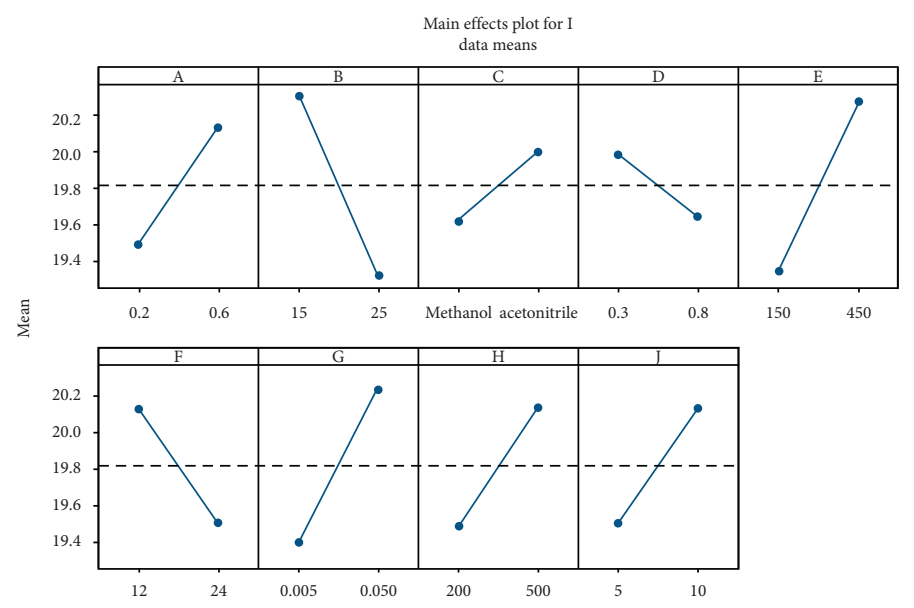

(b)

Figure 1: (a) The Pareto plot; (b) the main effect plot.

TABLE 2: The CCD matrix and the experimental results.

\begin{tabular}{lcccc}
\hline Run order & $\mathrm{B}$ & $\mathrm{E}$ & $\mathrm{G}$ & $\Delta I(\mu \mathrm{A})$ \\
\hline 1 & 10 & 300 & 0.03 & 20.43 \\
2 & 20 & 300 & 0.03 & 23.38 \\
3 & 10 & 600 & 0.03 & 20.32 \\
4 & 20 & 600 & 0.03 & 26.60 \\
5 & 10 & 300 & 0.07 & 29.22 \\
6 & 20 & 300 & 0.07 & 22.17 \\
7 & 10 & 600 & 0.07 & 26.01 \\
8 & 20 & 600 & 0.07 & 21.87 \\
9 & 15 & 450 & 0.05 & 22.78 \\
10 & 15 & 450 & 0.05 & 22.84 \\
11 & 15 & 450 & 0.05 & 25.46 \\
12 & 15 & 450 & 0.05 & 26.11 \\
13 & 10 & 450 & 0.05 & 25.01 \\
14 & 20 & 450 & 0.05 & 27.77 \\
15 & 15 & 300 & 0.05 & 25.73 \\
16 & 15 & 600 & 0.05 & 25.63 \\
17 & 15 & 450 & 0.03 & 25.32 \\
18 & 15 & 450 & 0.07 & 25.38 \\
19 & 15 & 450 & 0.05 & 25.73 \\
20 & 15 & 450 & 0.05 & 25.87 \\
\hline
\end{tabular}

TABLE 3: The ANOVA results for evaluation of mathematical models obtained by response surface design.

\begin{tabular}{lccccc}
\hline Source & DF $^{\mathrm{a}}$ & Adj. SS $^{\mathrm{b}}$ & Adj. MS $^{\mathrm{c}}$ & $F$ value & $P$ value \\
\hline Linear & 3 & 13.136 & 4.3788 & 59.49 & 0.001 \\
Square & 3 & 27.170 & 9.1495 & 124.30 & 0.001 \\
Interaction & 3 & 62.467 & 20.8224 & 282.89 & 0.001 \\
Lack-of-fit & 5 & 0.524 & 0.1049 & 2.48 & 0.171 \\
Pure error & 5 & 0.212 & 0.0424 & & \\
Total & 19 & 103.788 & & & \\
\hline
\end{tabular}

${ }^{\mathrm{a}}$ Degrees of freedom; ${ }^{\mathrm{b}}$ adjusted sum of squares; ${ }^{\mathrm{c}}$ adjusted mean squares.

the role of $\mathrm{GO}-\mathrm{Fe}_{3} \mathrm{O}_{4} @ \mathrm{SiO}_{2}$ nanocomposite in increasing the polymer surface area. In other words, GO- $\mathrm{Fe}_{3} \mathrm{O}_{4} @ \mathrm{SiO}_{2}$ forms a mediating layer between the MIP and the surface of the Pt electrode and increases the surface area of the electrode for electrochemical processes. In addition, it increases the conductivity of the electrode and facilitates the electron transfer process at the surface of the modified electrode [48].

2.1.5. Figures of Merit. In order to investigate the dependence of the analytical response of the proposed sensor on the concentration of MEL, different concentrations of MEL in optimal conditions were measured by the proposed MIP/ $\mathrm{GO}-\mathrm{Fe}_{3} \mathrm{O}_{4} @ \mathrm{SiO}_{2} / \mathrm{Pt}$ electrode. The calibration curve showed a dynamic linear range from $5.0 \times 10^{-7}$ to $1.0 \times 10^{-5} \mathrm{M}$ MEL (Figure 4 ), with a linear regression equation:

$$
\begin{aligned}
\Delta I & =2.5638+3.2143 C_{\mathrm{MEL}}, \\
R^{2} & =0.9997,
\end{aligned}
$$

where $C_{\mathrm{MEL}}$ is the MEL concentration and $\Delta I(\mu \mathrm{A})$ is the difference of $I_{p}$ and $I_{\mathrm{MIP}}$ voltammetric anodic peak current. The correlation coefficient is 0.9997 . The detection limit of MEL was obtained as $0.028 \mu \mathrm{M}$. The repeatability of the MIP/ GO-Fe3O4@SiO2/Pt electrode was investigated, and the $\Delta I$ was determined using the same electrode. The repeatability and reproducibility of the MIP/GO-Fe3O4@SiO2/Pt electrode were performed with repeated measurements of the same sensor in one day and repeated measurements with different sensors, respectively. Relative standard deviations (RSD\%) of $2.15 \%(n=4)$ and $6.43 \%(n=4)$ were obtained for repeatability and reproducibility, respectively. Interday stability of the sensor was investigated, and the current response was measured; the current was unaltered, and a decrease of $9.27 \%$ in the current response occurred after the 4th day. These results indicate that the electrode has an acceptable reproducibility and long-term stability, which make it attractive for fabrication of electrochemical sensors.

2.1.6. Selectivity of MIP/GO-Fe3O4@SiO2/Pt Electrode. In order to evaluate the proposed sensor selectivity, the $\Delta I$ was investigated for the solution containing $2.0 \times 10^{-6} \mathrm{M}$ MEL and different concentrations of each interfering molecules 


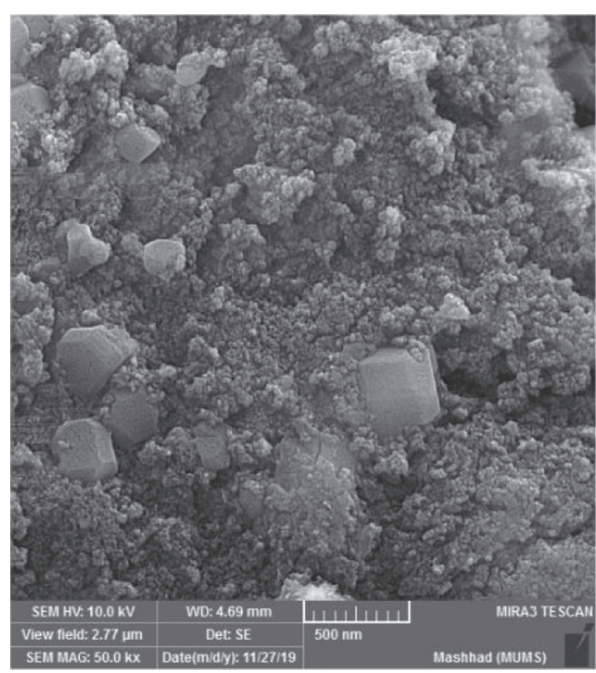

(a)

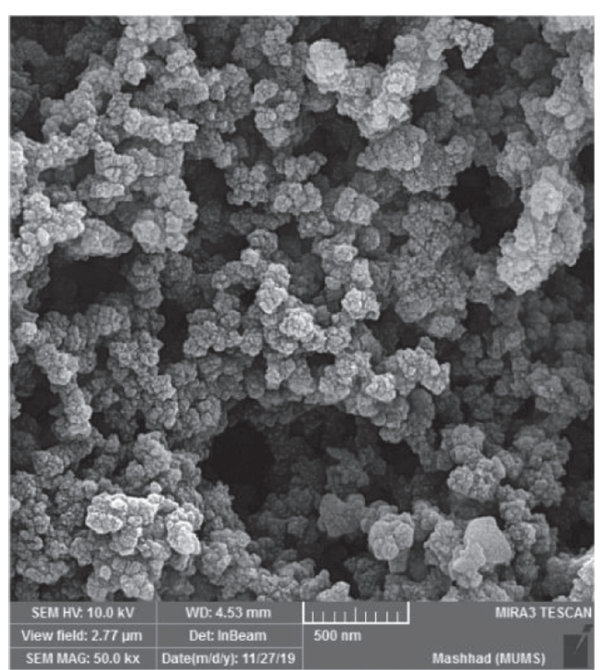

(b)

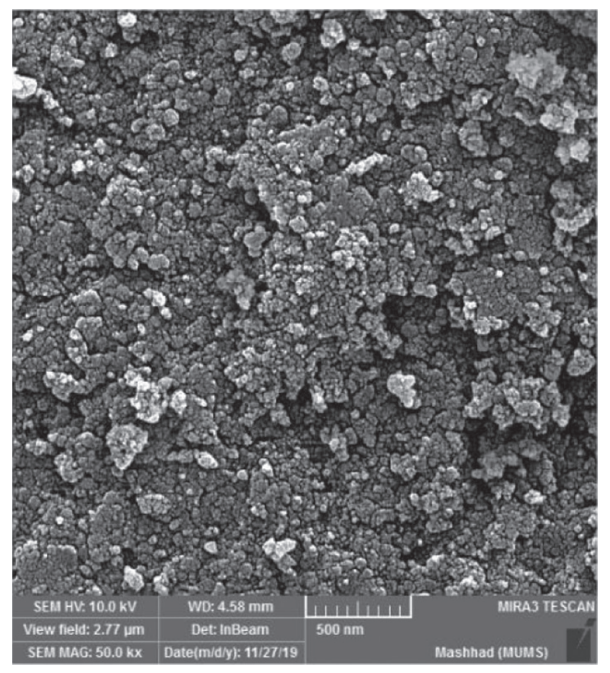

(c)

Figure 2: The SEM image of (a) GO-Fe $\mathrm{O}_{4} @ S i O 2$, (b) MIP/GO- $\mathrm{Fe}_{3} \mathrm{O}_{4} @ \mathrm{SiO}_{2}$, (c) and NIP/GO- $\mathrm{Fe}_{3} \mathrm{O}_{4} @ \mathrm{SiO}_{2}$.

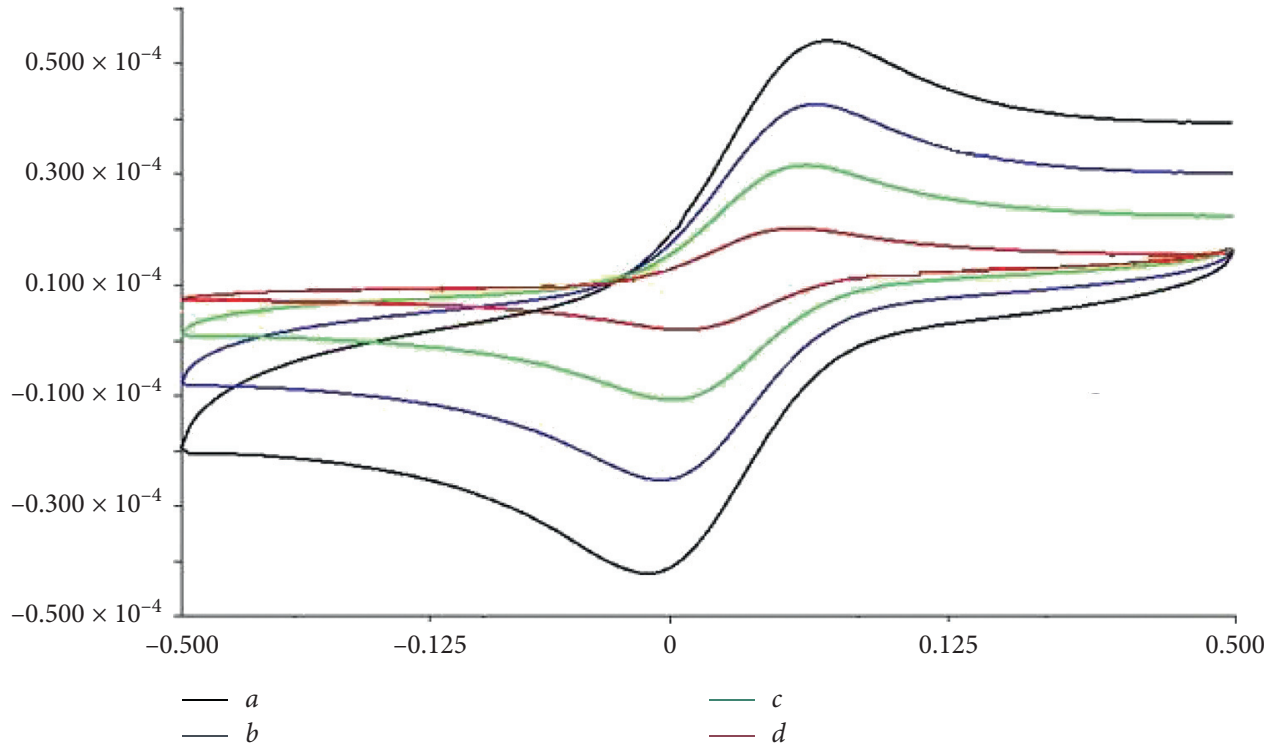

Figure 3: The CV voltammograms of the $0.3 \mathrm{M}$ probe solution at the surface (a) unloaded MIP/GO- $\mathrm{Fe}_{3} \mathrm{O}_{4} @ \mathrm{SiO}_{2} / \mathrm{Pt}$, (b) loaded NIP/GO$\mathrm{Fe}_{3} \mathrm{O}_{4} @ \mathrm{SiO}_{2} / \mathrm{Pt}$, (c) loaded MIP/Pt, and (d) loaded MIP/GO-Fe $\mathrm{O}_{4} @ \mathrm{SiO}_{2} / \mathrm{Pt}$. 


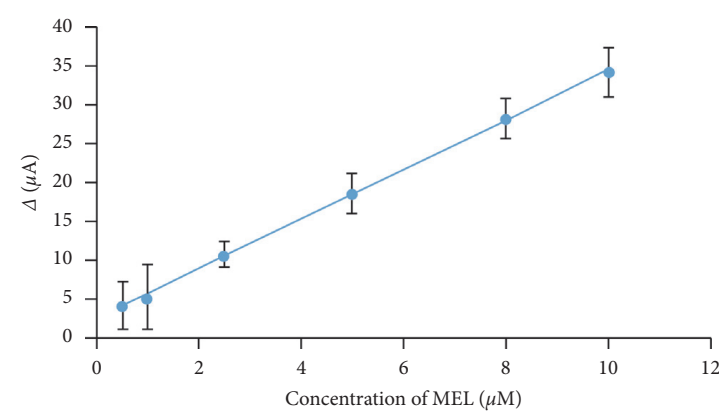

(a)

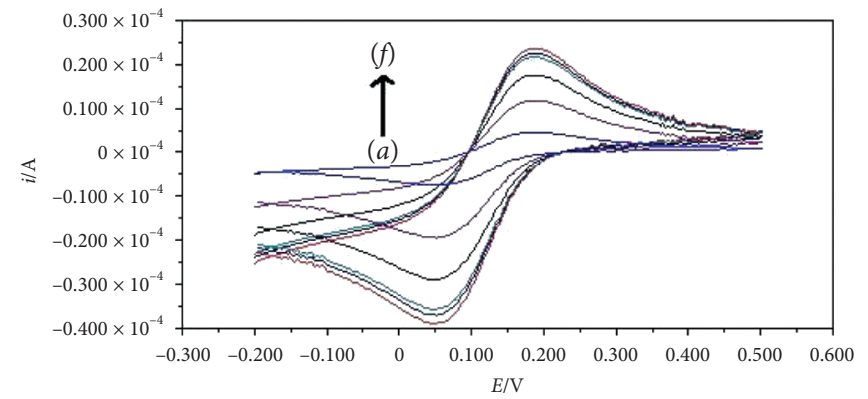

(b)

Figure 4: (a) The calibration curve of MEL in different concentrations and (b) the cyclic voltammograms of the $\mathrm{MIP} / \mathrm{GO}^{-} \mathrm{Fe} \mathrm{O}_{4} @ S i \mathrm{O}_{2} / \mathrm{Pt}$ electrode after loading in different solutions $(a: 8 \mu \mathrm{M}, b: 5 \mu \mathrm{M}, c: 2.5 \mu \mathrm{M}, d: 1 \mu \mathrm{M}, e: 0.5 \mu \mathrm{M}$, and $f: 0.1 \mu \mathrm{M})$ of MEL in $0.3 \mathrm{M}$ probe solution.

such as arginine, galactose, glucose, maltose, rabeprazole, and fluvoxamine. Table 4 shows the results of measurement of MEL in the presence of interfering molecules. The results confirm the selectivity of the MIP/GO- $-\mathrm{Fe}_{3} \mathrm{O}_{4} @$ $\mathrm{SiO}_{2} / \mathrm{Pt}$ electrode for the MEL relative to interfering substances.

2.1.7. Analysis of Food Samples. The method of standard addition is a type of quantitative analysis approach often used in analytical chemistry whereby the standard is added directly to the aliquots of analyzing samples. This method is used in situations, where the sample matrix also contributes to the analytical signal, a situation known as the matrix effect, thus making it impossible to compare the analytical signal between sample and standard using the traditional calibration curve approach. In the present procedure, three solutions containing $2 \mu \mathrm{M}$ of MEL and different amounts of standard solutions of MEL (0,2, and 4) were prepared and diluted to $10 \mathrm{~mL}$ with deionized water. Then, the proposed sensor was used for preconcentration and determination of MEL. Figure 5 shows the calibration curve for any food sample. Table 5 shows the results of measurement of MEL in milk, yoghurt, cheese, and dough samples. Each analysis was repeated three times under the optimized conditions. The recovery (\%) for the analyzed food samples showed good results $(92.5-104.5 \%)$.

\section{Experimental}

3.1. Chemicals and Reagents. Iron(III) chloride (99-102\%), iron(II) chloride (99.9999 Suprapur), hydrochloride acid (37\%), ammonia (99.5\%), pyrrole ( $\geq 97 \%)$, methanol (99.9\%), acetic acid (99.5\%), and ethanol (85\%) were purchased from Merck (Darmstadt, Germany). Potassium thiocyanate (99\%), potassium hexacyanoferrate (III) (99\%), potassium hexacyanoferrate (II) trihydrate (99.95\%), melamine (99\%), and sodium hydroxide (98\%) were purchased from Sigma-Aldrich. GO nanoparticles $(>95 \%)$ and $\mathrm{SiO}_{2}$ ('99\%) nanoparticles were purchased from Iranian Nanomaterials Pioneers Co. (Mashhad, Iran).
3.2. Apparatus. The electrochemical studies were done with a three-electrode system: a MIP/GO- $\mathrm{Fe}_{3} \mathrm{O}_{4} @ \mathrm{SiO}_{2} / \mathrm{Pt}$, a platinum wire, and an $\mathrm{Ag} / \mathrm{AgCl}$ (saturated $\mathrm{KCl}$ ) as the working electrode, the counterelectrode, and the reference electrode, respectively. The voltammetric measurements were carried out by Autolab PGSTAT 12 potentiostat-galvanostat (Ecochemie, The Netherlands). The surface evaluations of sensors were performed by scanning electron microscopy (SEM) in an Oxford S360 SEM (Britain) microscope. The sonication of GO- $\mathrm{Fe}_{3} \mathrm{O}_{4} @ \mathrm{SiO}_{2}$ was performed using a Hielscher ultrasonic bath processor (UTR200, Germany). Duo to shake of the extraction columns containing polymer and loading solution during the extraction process, Shaker KS130 EKE (Germany) was used.

3.2.1. Synthesis of $\quad \mathrm{GO}-\mathrm{Fe}_{3} \mathrm{O}_{4} @ \mathrm{SiO}_{2} \quad$ Nanocomposite. $\mathrm{GO}-\mathrm{Fe}_{3} \mathrm{O}_{4} @ \mathrm{SiO}_{2}$ nanocomposite was prepared in two steps. In the first step, $\mathrm{GO}-\mathrm{Fe}_{3} \mathrm{O}_{4}$ nanocomposite was synthesized based on a chemical coprecipitation method [48] as follows: $0.5 \mathrm{~g}$ of GO powder was added to $100 \mathrm{~mL}$ of distilled water at $70^{\circ} \mathrm{C}$ and stirred using a magnetic magnet. Then, a mixture of $16.0 \mathrm{~g}$ of $\mathrm{FeCl}_{3} \cdot 6 \mathrm{H}_{2} \mathrm{O}$ and $0.8 \mathrm{~g}$ of $\mathrm{FeCl}_{2} \cdot 4 \mathrm{H}_{2} \mathrm{O}$ was added to the above mixture at $70^{\circ} \mathrm{C}$. Then, the $\mathrm{pH}$ of the resulting suspension was adjusted to 12 by ammonia solution. The mixture was stirred for 1 hour at $70^{\circ} \mathrm{C}$. Then, the resulting black precipitate, after cooling, was washed three times with distilled water and ethanol and dried for 6 hours at $60^{\circ} \mathrm{C}$. In the second step, $2.0 \mathrm{~g}$ of $\mathrm{GO}-\mathrm{Fe}_{3} \mathrm{O}_{4}$ nanocomposite was added to $400 \mathrm{~mL}$ of distilled water and stirred at $8^{\circ} \mathrm{C}$ for $30 \mathrm{~min}$. Afterward, $40 \mathrm{~mL}$ of silicate solution $(1.0 \mathrm{M})$ resulted from a 2-hour reflux of $4.22 \mathrm{~g}$ of $\mathrm{SiO}_{2}, 2.0 \mathrm{~g}$ of $\mathrm{NaOH}$, and $40 \mathrm{~mL}$ of distilled water at $80^{\circ} \mathrm{C}$ was added into the initial solution. The $\mathrm{pH}$ of the resulting solution was adjusted to 6.0 using $\mathrm{HCl}$ and refluxed at $80^{\circ} \mathrm{C}$ for 6 hours. The resulting precipitate was isolated using magnets and washed with distilled water and dried at $60^{\circ} \mathrm{C}$ for 2 hours.

3.2.2. Fabrication of $\mathrm{MIP} / \mathrm{GO}-\mathrm{Fe}_{3} \mathrm{O}_{4} @ \mathrm{SiO}_{2}$ Nanocomposite. For synthesis of MIP/GO-Fe $\mathrm{O}_{4} @ \mathrm{SiO}_{2}$ nanocomposite, $0.6 \mathrm{~g}$ $\mathrm{GO}-\mathrm{Fe}_{3} \mathrm{O}_{4} @ \mathrm{SiO}_{2}$ nanocomposite was dispersed in $5 \mathrm{~mL}$ of 
TABLE 4: Selectivity of sensor MEL $\left(2.0 \times 10^{-6} \mathrm{M}\right)$ in presence of interfering molecules.

\begin{tabular}{lccc}
\hline Interfering molecule & MEL : interfering molecule & Change in current response for detection of $2.0 \times 10^{-6} \mathrm{M}$ MEL & Recovery $(\%)$ \\
\hline \multirow{2}{*}{ Arginine } & $1: 1$ & -0.421 & 88.16 \\
& $1: 2$ & -0.133 & 96.27 \\
& $1: 4$ & -0.224 & 93.72 \\
Galactose & $1: 1$ & +0.039 & 101.10 \\
& $1: 2$ & -0.309 & 91.33 \\
Glucose & $1: 4$ & -0.338 & 90.50 \\
& $1: 1$ & -0.100 & 97.19 \\
Maltose & $1: 2$ & -0.234 & 93.43 \\
& $1: 4$ & +0.098 & 102.77 \\
Rabeprazole & $1: 1$ & -0.462 & 87.02 \\
& $1: 2$ & -0.322 & 90.96 \\
Fluvoxamine & $1: 4$ & -0.257 & 92.79 \\
& $1: 1$ & -0.230 & 93.54 \\
& $1: 2$ & -0.328 & 90.80 \\
& $1: 4$ & -0.421 & 88.16 \\
& $1: 1$ & -0.261 & 92.65 \\
\end{tabular}

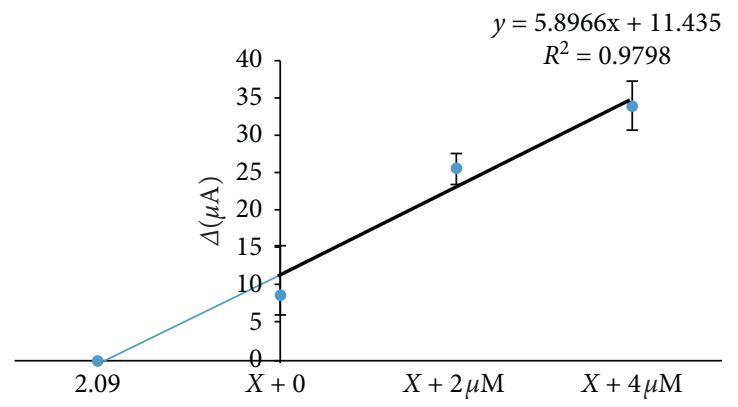

(a)

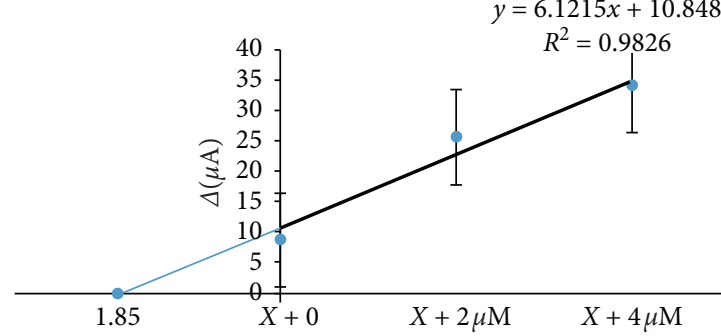

(c)

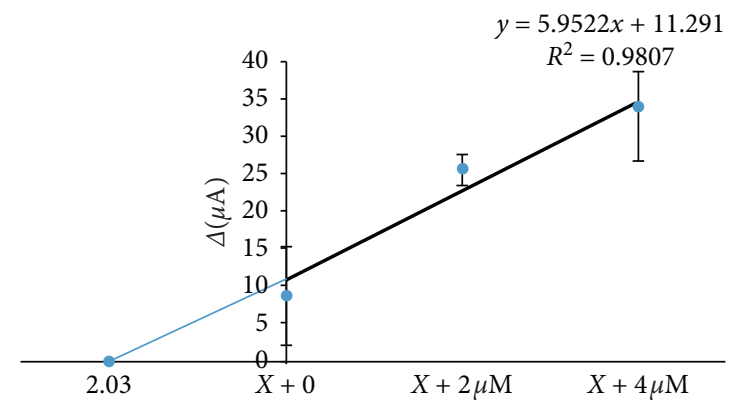

(b)

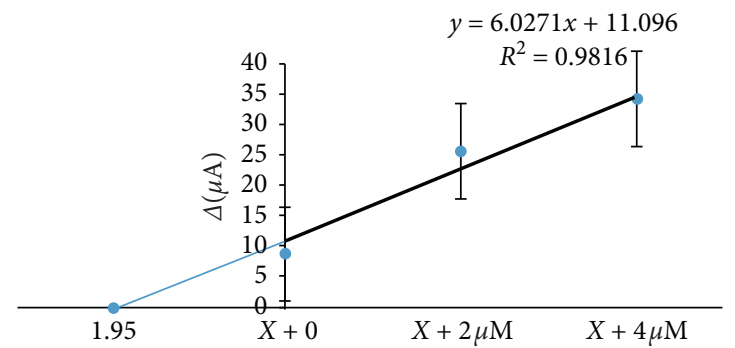

(d)

FIGURE 5: The calibration curve for (a) milk, (b) yoghurt, (c) cheese, and (d) dough.

TABLE 5: The results of MEL determination in food sample analysis.

\begin{tabular}{lccc}
\hline Sample & $\begin{array}{c}\text { MEL added } \\
(\mu \mathrm{M})\end{array}$ & $\begin{array}{c}\text { Average of MEL found } \\
(\mu \mathrm{M})\end{array}$ & $\begin{array}{c}\text { Recovery } \\
(\%)\end{array}$ \\
\hline \multirow{2}{*}{ Milk } & 0 & Not detected & - \\
& 2.0 & 2.09 & 104.5 \\
Yoghurt & 0 & Not detected & - \\
& 2.0 & 2.03 & 101.5 \\
Cheese & 0 & Not detected & - \\
& 2.0 & 1.85 & 92.5 \\
Dough & 0 & Not detected & - \\
& 2.0 & 1.95 & 95.0 \\
\hline
\end{tabular}

acetonitrile for $10 \mathrm{~min}$. Then, $0.012 \mathrm{~mL}$ of pyrrole, as a functional monomer, and $0.0006 \mathrm{~g}$ of MEL, as a template molecule, were added to the above suspension. Then, $0.3 \mathrm{~g}$ $\mathrm{FeCl}_{3}$, as the initiator, was added and was stirred in 300 r.p.m for 12 hours. Afterward, the black precipitate was collected using a magnet and was washed with deionized water. Then, the initiator removal test was performed by potassium thiocyanate. To remove MEL from the polymer structure, the black solid polymer produced by the 2:8 (V/V) acetic acid: methanol solvent was thoroughly washed until the absorbance of the extracted solution at $238 \mathrm{~nm}$ wavelength 
TABLE 6: Comparison of the results of different techniques on determination of MEL.

\begin{tabular}{lcccc}
\hline Technique & Detection method & Linear range $(\mathrm{M})$ & LOD $(\mu \mathrm{M})$ & Reference \\
\hline HPLC & UV & $7.9 \times 10^{-6}-6.3 \times 10^{-4}$ & 0.79 & {$[7]$} \\
Ion-selective electrode & Potentiometry & $5.0 \times 10^{-6}-1.0 \times 10^{-2}$ & 1.6 & {$[50]$} \\
Gas chromatography & Mass spectrometry & $4.0 \times 10^{-7}-1.58 \times 10^{-5}$ & 0.08 & 0.0028 \\
MIP & CV & $5.0 \times 10^{-7}-1.0 \times 10^{-5}$ & {$[51]$} & This work \\
\hline
\end{tabular}

UV reached less than 0.005. After that, $\mathrm{MIP} / \mathrm{GO}-\mathrm{Fe}_{3} \mathrm{O}_{4} @$ $\mathrm{SiO}_{2}$ nanocomposite was dried at $60^{\circ} \mathrm{C}$ for 2 hours. For nonimprinted polymer (NIP) preparation, polymerization was carried out in the absence of MEL.

3.2.3. Fabrication of $\mathrm{MIP} / \mathrm{GO}-\mathrm{Fe}_{3} \mathrm{O}_{4} @ \mathrm{SiO}_{2} / \mathrm{Pt}$ Electrode. To make the MIP/GO-Fe $\mathrm{O}_{4} @ \mathrm{SiO}_{2} / \mathrm{Pt}$ electrode, $0.07 \mathrm{~g}$ of nanocomposite was dispersed in $1.0 \mathrm{~mL}$ ethanol and was contacted with the surface of the Pt electrode. The electrode was dried at room temperature. Then, the resulting electrode was used as the working electrode in the electrochemical measurements.

3.3. Electroanalytical Measurements. The voltammetric measurements were done in a three-electrode system in the $0.3 \mathrm{M}$ solution of $\left[\mathrm{Fe}(\mathrm{CN})_{6}\right]^{4-}$ and $\left[\mathrm{Fe}(\mathrm{CN})_{6}\right]^{3-}$. CV cycles were recorded from $-0.5 \mathrm{~V}$ to $+0.5 \mathrm{~V}$ at the scan rate of $8.0 \mathrm{mV} / \mathrm{s}$, applying a step potential of $0.00405 \mathrm{~V}$ and modulation amplitude of $0.4995 \mathrm{~V}$, at room temperature.

3.4. Sample Preparation. To evaluate the accuracy of the proposed method, $1.0 \mathrm{~g}$ food sample (milk, yoghurt, cheese, and dough) was spiked with a MEL standard solution to give a working concentration of MEL $(0.0,2.0$, and $4.0 \mu \mathrm{M})$. This sample was placed into a 5 Eppendorf Safe-Lock microcentrifuge tubes, including $4 \mathrm{~mL}$ of acetonitrile, then vortexed for $10 \mathrm{~s}$, and finally was sonicated for 30 minutes. After that, the mixture was centrifuged at 2500 r.p.m. for 5 minutes to eliminate serum protein. The clear solution was transferred into a volumetric flask and fixed to $10 \mathrm{~mL}$ using deionized water [49].

\section{Conclusion}

In this study, an electrochemical sensor was developed for the determination of MEL. Chemical polymerization of pyrrole was carried out in the presence of MEL, and then, by removing the MEL from the MIP holes, it deposited on the bare Pt electrode to construct the electrochemical sensor as a selective and sensitive microsolid-phase preconcentration sensor for the determination of MEL. Screening of effective factors and their optimization was performed with multivariate optimization methods. The sensor was used for analysis of milk, yoghurt, cheese, and dough samples. It is noteworthy that the quick and easy-to-make renewal of the electrode, short incubation time, the characteristics of low detection limit $(0.028 \mu \mathrm{M})$, wide range $\left(5.0 \times 10^{-7}\right.$ to $1.0 \times 10^{-5} \mathrm{M}$ ), good repeatability (RSD $2.15 \%$ ) and reproducibility (RSD 6.43\%), simple fabrication, and low cost are the predominant advantages of the proposed sensor over the other existing methods of MEL analysis. The comparison between the analytical characteristics of the present sensor and some pervious reported technique for the determination of MEL is listed in Table $6[7,50,51]$.

\section{Data Availability}

No data were used to support this study.

\section{Conflicts of Interest}

The authors declare that there are no conflicts of interest regarding the publication of this paper.

\section{Acknowledgments}

The authors would like to express our sincere gratitude to Research Office, Mashhad Branch, Payame Noor University, Mashhad, Iran, for financial support of this work.

\section{References}

[1] S. Bizzari and K. Yokose, Melamine, in: Chemical Economics Handbook, SRI Consulting Inc., Fairfax, VA, USA, 2008.

[2] A. Pizzi and K. L. Mittal, Handbook of Adhesive Technology, Revised and Expanded, CRC Press, Boca Raton, FL, USA, 2003.

[3] Y.-C. Tyan, M.-H. Yang, S.-B. Jong, C.-K. Wang, and J. Shiea, "Melamine contamination," Analytical and Bioanalytical Chemistry, vol. 395, no. 3, pp. 729-735, 2009.

[4] Z. Chen and X. Yan, "Simultaneous determination of melamine and 5-hydroxymethylfurfural in milk by capillary electrophoresis with diode array detection," Journal of Agricultural and Food Chemistry, vol. 57, no. 19, pp. 8742-8747, 2009.

[5] Q. Wu, K. Fan, W. Sha, H. Ruan, R. Zeng, and C. Shieh, "Highly sensitive detection of melamine based on reversed phase liquid chromatography mass spectrometry," Science Bulletin, vol. 54, no. 5, pp. 732-737, 2009.

[6] H. A. Cook, C. W. Klampfl, and W. Buchberger, "Analysis of melamine resins by capillary zone electrophoresis with electrospray ionization-mass spectrometric detection," Electrophoresis, vol. 26, no. 7-8, pp. 1576-1583, 2005.

[7] G. Venkatasami and J. R. Sowa Jr., "A rapid, acetonitrile-free, HPLC method for determination of melamine in infant formula," Analytica Chimica Acta, vol. 665, no. 2, pp. 227-230, 2010.

[8] L. Zhu, G. Xu, F. Wei, J. Yang, and Q. Hu, "Determination of melamine in powdered milk by molecularly imprinted stir bar sorptive extraction coupled with HPLC," Journal of Colloid and Interface Science, vol. 454, pp. 8-13, 2015. 
[9] Y. Li, J. Xu, and C. Sun, "Chemical sensors and biosensors for the detection of melamine," RSC Advances, vol. 5, no. 2, pp. 1125-1147, 2015.

[10] Q. Cao, H. Zhao, Y. He et al., "Hydrogen-bonding-induced colorimetric detection of melamine by nonaggregation-based Au-NPs as a probe," Biosensors and Bioelectronics, vol. 25, no. 12, pp. 2680-2685, 2010.

[11] T. Alizadeh and L. Allahyari, "Highly-selective determination of carcinogenic derivative of propranolol by using a carbon paste electrode incorporated with nano-sized propranololimprinted polymer," Electrochimica Acta, vol. 111, pp. 663673, 2013.

[12] A. Nakhaei and S. Ramezani, "Synthesis, characterization, and theoretical studies of the new antibacterial $\mathrm{Zn}(\mathrm{II})$ complexes from new fluorescent schiff bases prepared by imidazo $\left[4^{\prime}, 5^{\prime}\right.$ : 3,4]benzo[1,2-c]isoxazole," Iran Journal of Chemistry and Chemical Engineering, vol. 38, no. 4, pp. 79-90, 2019.

[13] D. Kumar and B. B. Prasad, "Multiwalled carbon nanotubes embedded molecularly imprinted polymer-modified screen printed carbon electrode for the quantitative analysis of C-reactive protein," Sensors and Actuators B: Chemical, vol. 171-172, pp. 1141-1150, 2012.

[14] A. Nakhaei, A. Davoodnia, and S. Yadegarian, "NanoFe3O4@ZrO2-SO3H as highly efficient recyclable catalyst for the green synthesis of fluoroquinolones in ordinary or magnetized water," Iranian Journal of Catalysis, vol. 8, no. 1, pp. 47-52, 2018.

[15] M. B. Gholivand, M. Torkashvand, and G. Malekzadeh, "Fabrication of an electrochemical sensor based on computationally designed molecularly imprinted polymers for determination of cyanazine in food samples," Analytica Chimica Acta, vol. 713, pp. 36-44, 2012.

[16] S. Ge, M. Yan, X. Cheng et al., "On-line molecular imprinted solid-phase extraction flow-injection fluorescence sensor for determination of florfenicol in animal tissues," Journal of Pharmaceutical and Biomedical Analysis, vol. 52, no. 4, p. 615, 2010.

[17] S. M. Borisov, T. Mayr, G. Mistlberger, K. Waich, K. Koren, and P. Chojnacki, "Precipitation as a simple and versatile method for preparation of optical nanochemosensors," Talanta, vol. 79, no. 5, pp. 1322-1330, 2009.

[18] J. Hu, H. Dai, Y. Zeng et al., “A cross-linker-based poly(ionic liquid) for sensitive electrochemical detection of 4-nonylphenol," Nanomaterials, vol. 9, p. 513, 2019.

[19] L. Li, T. Xue-cai, Z. Dan-dan, W. Lin, L. Fu-hou, and H. Zaiyin, Chemical Research in Chinese Universities, p. 410, Elsevier, Amsterdam, Netherlands, 2012.

[20] M. Salgarello, G. Visconti, and L. Barone-Adesi, "Interlocking circumareolar suture with undyed polyamide thread: a personal experience," Aesthetic Plastic Surgery, vol. 37, no. 5, p. $1061,2013$.

[21] Y. Barone-Adesi, Z. Zhang, V. Jain et al., "Potentiometric sensors based on surface molecular imprinting: detection of cancer biomarkers and viruses," Sensors and Actuators B: Chemical, vol. 146, no. 1, p. 381, 2010.

[22] B. B. Prasad, R. Madhuri, and M. P. Tiwari, "Imprinted polymer-carbon consolidated composite fiber sensor for substrate-selective electrochemical sensing of folic acid," Biosensors and Bioelectronics, vol. 25, no. 9, p. 2140, 2010

[23] E. Kazemi, A. Davoodnia, A. Nakhaei, S. Basafa, and N. Tavakoli-Hoseini, "Investigating effect of cerium (IV) sulfate tetrahydrate as reusable and heterogeneous catalyst for the one-pot multicomponent synthesis of polyhydroquinolines," Advanced Journal of Chemistry A, vol. 1, no. 2, pp. 96-104, 2018.

[24] A. Nakhaei and Z. Nakhaei, "Synthesis of carbamatoalkyl napthols using $\mathrm{Fe}_{3} \mathrm{O}_{4} @ \mathrm{ZrO}_{2}-\mathrm{SO}_{3} \mathrm{H}$ as highly efficient and magnetically recyclable nano-catalyst," Heterocyclic Letters, vol. 7, no. 3, pp. 565-572, 2017.

[25] B. B. Prasad, R. Madhuri, M. P. Tiwari, and P. S. Sharma, "Enantioselective recognition of $\mathrm{d}$ - and l-tryptophan by imprinted polymer-carbon composite fiber sensor," Talanta, vol. 81, no. 1-2, pp. 187-196, 2010.

[26] J. M. Kim, H.-I. Joh, S. M. Jo et al., "Preparation and characterization of $\mathrm{Pt}$ nanowire by electrospinning method for methanol oxidation," Electrochimica Acta, vol. 55, no. 16, pp. 4827-4835, 2010.

[27] A. Nakhaei and S. Yadegarian, "An efficient synthesis of 14substituted-14H-dibenzo [a, j] xanthene derivatives promoted by a nano isopolyoxomolybdate under thermal and solventfree conditions," Iranian Journal of Organic Chemistry, vol. 9, pp. 2057-2065, 2017.

[28] M. Pumera, "The electrochemistry of carbon nanotubes: fundamentals and applications," Chemistry-A European Journal, vol. 15, no. 20, p. 4970, 2009.

[29] H. Beitollahi, H. Karimi-Maleh, and H. Khabazzadeh, "Nanomolar and selective determination of epinephrine in the presence of norepinephrine using carbon paste electrode modified with carbon nanotubes and novel 2-(4-oxo-3phenyl-3,4-dihydro-quinazolinyl)- $\mathrm{N}^{\prime}$-phenyl-hydrazinecar bothioamide," Analytical Chemistry, vol. 80, no. 24, p. 9848, 2008.

[30] A. Nakhaei and Z. Nakhaei, "Carbon based solid acid as a highly efficient," Heterocyclic Letters, vol. 7, pp. 605-611, 2017.

[31] J. Wackerlig and P. A. Lieberzeit, "Molecularly imprinted polymer nanoparticles in chemical sensing-synthesis, characterisation and application," Sensors and Actuators B: Chemical, vol. 207, p. 144, 2015.

[32] E. Asadi, S. Azodi-Deilami, M. Abdouss, and S. Khaghani, "Cyproterone synthesis, recognition and controlled release by molecularly imprinted nanoparticle," Applied Biochemistry and Biotechnology, vol. 167, no. 7, p. 2076, 2012.

[33] F. Canfarotta and M. J. Whitcombe, "Polymeric nanoparticles for optical sensing," Biotechnology Advances, vol. 31, no. 8, p. 1585, 2013.

[34] A. Nakhaei, Heterocyclic Letters, vol. 7, no. 4, pp. 967-973, 2017.

[35] S. Akgönüllü, H. Yavuz, and A. Denizli, "SPR nanosensor based on molecularly imprinted polymer film with gold nanoparticles for sensitive detection of aflatoxin B1," Talanta, vol. 219, Article ID 121219, 2020.

[36] S. Akgönüllü, D. Battal, M. S. Yalcin, H. Yavuz, and A. Denizli, "Rapid and sensitive detection of synthetic cannabinoids JWH-018, JWH-073 and their metabolites using molecularly imprinted polymer-coated QCM nanosensor in artificial saliva," Microchemical Journal, vol. 153, p. 104454, 2020.

[37] A. C. Bartnik, F. W. Wise, A. Kigel, and E. Lifshitz, "Electronic structure of $\mathrm{PbSe} / \mathrm{PbS}$ core-shell quantum dots," Physical Review B, vol. 75, p. 245424, 2007.

[38] R. Ayşegül, S. Akgönüllü, S. Karacan, and A. Denizli, "Biomimetic nanoparticles based surface plasmon resonance biosensors for histamine detection in foods," ChemistrySelect, vol. 5, pp. 5683-5692, 2020.

[39] J. T. Ritzert, G. Minasov, R. Embry, M. J. Schipma, and K. J. F. Satchell, "The cyclic AMP receptor protein regulates quorum sensing and global gene expression in yersinia pestis during planktonic growth and growth in biofilms," Modern 
Computer Tools for the Biosciences, vol. 10, no. 6, Article ID e02613, 2019.

[40] Y. Wang, H. Xu, W. Qiang, H. Gu, and D. Shi, “Asymmetric composite nanoparticles with anisotropic surface functionalities," Journal of Nanomaterials, vol. 2009, Article ID 620269, 5 pages, 2009.

[41] A. Nakhaei, S. Shojaee, E. Yaghoobi, and S. Ramezani, "Fast and green synthesis of 3, 4-dihydropyrimidin-2 (1h)-ones and-thiones using nanometasilica disulfuric acid as recyclable catalyst in water," Heterocyclic Letters, vol. 7, pp. 323-331, 2017.

[42] P. S. Joshi and D. S. Sutrave, "A brief study of cyclic voltammetry and electrochemical analysis," International Journal of ChemTech Research, vol. 11, no. 9, p. 77, 2018.

[43] C. R. T. Tarley, G. Silveira, W. N. L. dos Santos et al., "Chemometric tools in electroanalytical chemistry: methods for optimization based on factorial design and response surface methodology," Microchemical Journal, vol. 92, no. 1, p. 58, 2009.

[44] J. Ferreira, J. P. Cheng, M. Li, L. Liu, F. Liu, and X. B. Zhang, "Flower-like nickel-cobalt binary hydroxides with high specific capacitance: tuning the composition and asymmetric capacitor application," Journal of Electroanalytical Chemistry, vol. 743, p. 38, 2015.

[45] B. Grunden and J. O. Iroh, "Formation of graphite fibrepolypyrrole coatings by aqueous electrochemical polymerization," Polymer, vol. 36, no. 3, pp. 559-563, 1995.

[46] M. Roushani, A. Nezhadali, Z. Jalilian, and A. Azadbakht, "Development of novel electrochemical sensor on the base of molecular imprinted polymer decorated on $\mathrm{SiC}$ nanoparticles modified glassy carbon electrode for selective determination of loratadine," Materials Science and Engineering: C, vol. 71, p. 1106, 2017.

[47] S. Kunath, N. Marchyk, and K. Haupt, "Multi-objective optimization and design of experiments as tools to tailor molecularly imprinted polymers specific for glucuronic acid," Talanta, vol. 105, p. 211, 2013.

[48] H. Beitollahi, F. G. Nejad, and S. Shakeri, “GO/Fe3O4@SiO2 core-shell nanocomposite-modified graphite screen-printed electrode for sensitive and selective electrochemical sensing of dopamine and uric acid," Analytical Methods, vol. 9, no. 37, pp. 5541-5549, 2017.

[49] M. Hashemi and Z. Nazari, "Preparation of molecularly imprinted polymer based on the magnetic multiwalled carbon nanotubes for selective separation and spectrophotometric determination of melamine in milk samples," Journal of Food Composition and Analysis, vol. 69, p. 98, 2018.

[50] R. Liang, R. Zhang, and W. Qin, "Potentiometric sensor based on molecularly imprinted polymer for determination of melamine in milk," Sensors and Actuators B: Chemical, vol. 141, no. 2, p. 544, 2009.

[51] X. M. Xu, Y. P. Ren, Y. Zhu et al., "Direct determination of melamine in dairy products by gas chromatography/mass spectrometry with coupled column separation," Analytica Chimica Acta, vol. 650, no. 1, pp. 39-43, 2009. 